\title{
Belonging as a Resource of Resilience: Psychological Wellbeing of International and Refugee Students in Study Preparation at German Higher Education Institutions
}

\author{
Michael Grüttner \\ German Centre for Higher Education Research and Science Studies (DZHW), Hanover, Germany
}

\begin{abstract}
After 2015, several German higher education institutions (HEI) expanded their capacities for the study preparation of refugees. Nowadays, international and refugee students prepare for higher education degree programs through languages courses and subject-specific preparation courses at universities and colleges. So far, empirical research on refugee students' wellbeing, in comparison to international students is scarce. This article elaborates on study preparation at German HEIs and refugee students' psychological wellbeing. I focus on the mechanisms of subjective social exclusion/inclusion. I examine novel survey data from international and refugee students (final sample $\mathrm{N}=904$ ) by path analysis structural equation modelling. Results show on one hand that feelings of social exclusion reduce wellbeing, but on the other hand course belonging can function as a social resource of resilience for refugee students in study preparation. HEIs can strengthen feelings of social inclusion and psychological wellbeing of refugee students by fostering their belongingness in study preparation courses.
\end{abstract}

Keywords: Social exclusion and inclusion; refugee students; study preparation; psychological wellbeing; resilience.

\section{Introduction}

In recent years, Germany has become one of the most popular destinations for international students worldwide. More than 370,000 international students were enrolled at German higher education institutions (HEIs) for the winter semester of 2017/2018 (Federal Statistical Office, 2018). Even if some of them had already acquired the prerequisites at home, a large section of them had to manage through a language or subject-specific study preparation at their chosen destination (Apolinarski \& Brandt, 2018). Simultaneously, many recently arrived refugees in Germany are longing for social integration and thus, seeking access to HEIs. The German federal government funded support measures and study preparation programs at German universities, universities of applied sciences and the so called 'Studienkollegs' (Grüttner, Berg, \& Schröder, 2018).

So far, evidence on success and the wellbeing of international and refugee students in study preparation, in Germany, is scarce. ${ }^{1}$ Moreover, research on the wellbeing of international students seems to be concentrated in the United States, United Kingdom

${ }^{1}$ There are few research articles on study preparation of refugees and aspects of wellbeing, for example Brooker and Lawrence (2012) or Baker and others (2018).

This work is licensed under a Creative Commons Attribution 4.0 International Licence. As an open access journal, articles are free to use with proper attribution. ISSN: 2205-0795 
and Australia, rather than in Germany (except Akhtar \& Kroener-Herwig, 2015; 2017). The present study addresses this research gap by elaborating on the determinants of the wellbeing of international and refugee students at study preparation courses at German HEIs. This is of great importance, since highly qualified and skilled refugees in Germany tend to report low subjective wellbeing indicators (Hahn, Richter, Schupp, \& Back, 2019). In this article we examined (1) how feelings of social exclusion or inclusion correlate with the psychological wellbeing of international and refugee students, and (2) whether social and personal resources, such as social support, course belonging and resilience, can foster their social inclusion and wellbeing and buffer the detrimental effects of social exclusion.

Recent research has illustrated how "racism pervades the educational experiences" (Molla, 2019, para. 1). After the summer of migration in 2015, Germany experienced a resurgence of xenophobic and racist tendencies, which were directed, in particular, towards muslims and refugees. Therefore, the focus is on xenophobia and discrimination as mechanisms of social exclusion of migrant populations in Germany. This article examines refugee and international student experiences of social exclusion/inclusion (Bude \& Lantermann, 2006; Byrne, 2005) and whether these impact on psychological wellbeing (Leary, 1990; Williams, 2007). Moreover, the article distinguishes between the feeling of social inclusion in society and student selfidentification as two distinct, but interrelated, indicators of social inclusion.

\section{Migration Channels, Mechanisms of Social Exclusion/Inclusion, and Wellbeing Amongst Refugee Students}

Examining refugee and international student wellbeing from a social exclusion/inclusion perspective (Bude \& Lantermann, 2006; Byrne, 2005), means conceptualising social exclusion/inclusion as a multidimensional and somewhat subjective phenomenon, and looking at the concrete social mechanisms that trigger social exclusion, relating to psychological wellbeing (Leary, 1990; Williams, 2007). Refugee students differ from other international students due to distinct institutionally framed migration pathways and contexts, and the related system of asylum they have been though. This migration channel shapes their ongoing situation in the country of residence (Findlay, 1990; Sandoz, 2018). For refugee students the security of life was a much more salient migration motive than higher education. They must cope with interrupted or fragmented educational and occupational careers, while international students typically do not undergo such issues. In this combined experience of migration and education, perceived discrimination or social undermining can suppress feelings of social belonging and identification, which are crucial for the proper wellbeing of international students and young refugees (Chen, Mallinchrodt, \& Mobley, 2002; Correa-Velez, Gifford, \& McMichael, 2015; Jung, Hecht, \& Wadsworth, 2007; Molla, 2019). Therefore, it can be hypothesised that worries about xenophobia lead to less feelings of belonging to society and that worries about discrimination within higher education institutions reduce the feeling of belonging to the group of university students (see Figure 1). Due to the social deprivation of the asylum system (Griffiths, \& Sigona, 2005; Täubig, 2019; Zetter), it is likely that refugee students have less social resources. If they view their engagement with higher education as an investment in a new life in the host country, and a part of a long-term integration strategy (Grüttner et al., 2018), their wellbeing should be more dependent on social belonging in general than student belonging in particular. One of our study participants questioned the notion of integration and stated: "higher education means integration". ${ }^{2}$

\section{Personal coping and Resilience may Impact on Perceived Inclusion/Exclusion and Wellbeing}

However, resilience literature suggests that any negative effects of external environmental conditions, and their perception (e.g. perceived xenophobia or anticipated discrimination) on psychological wellbeing, may depend on the social and personal resources of resilience and coping behaviours available to the actors (Lazarus \& Folkman, 1984; Ungar \& Hadfield, 2019). Refugee students may report higher levels of resilient coping, compared to international students, because of different conditions of the migration decisions and selection; flight, inherently, is a manifestation of resilient coping. Resilience unfolds its effects, by definition, against the backdrop of unfavourable situations, but people can also gain and use resources to cope (Hobfoll 2001).

Therefore, personal resources should be positively related to wellbeing (Akhtar \& Kroener-Herwig, 2017, for coping styles), fostering social resources, and strengthening indicators of social inclusion (Bude \& Lantermann, 2006). I propose that the association between worries about xenophobia in Germany and discrimination at HEIs with psychological wellbeing is mediated to some extent by a sense of social belonging and student belonging. While social resources, beyond the direct effects

\footnotetext{
${ }^{2}$ We conducted qualitative interviews and a focus group with refugees participating in preparatory courses at a German university and a 'Studienkolleg' (see Grüttner et al., 2018).
} 
on social inclusion and wellbeing, ease worries about xenophobia and discrimination, personal resources buffer the detrimental effects of xenophobia and discrimination on wellbeing by strengthening social inclusion against adverse circumstances. With respect to resilience (Ungar \& Hadfield, 2019), this article tests the proposition that social and personal resources buffer the effects of social exclusion on wellbeing (Chen et al., 2002; Sullivan \& Kashubeck-West, 2015). These relationships are summarised in Figure 1.

\section{Figure 1}

Conceptual Model of Social and Personal Resources, Social Exclusion/Inclusion and Wellbeing

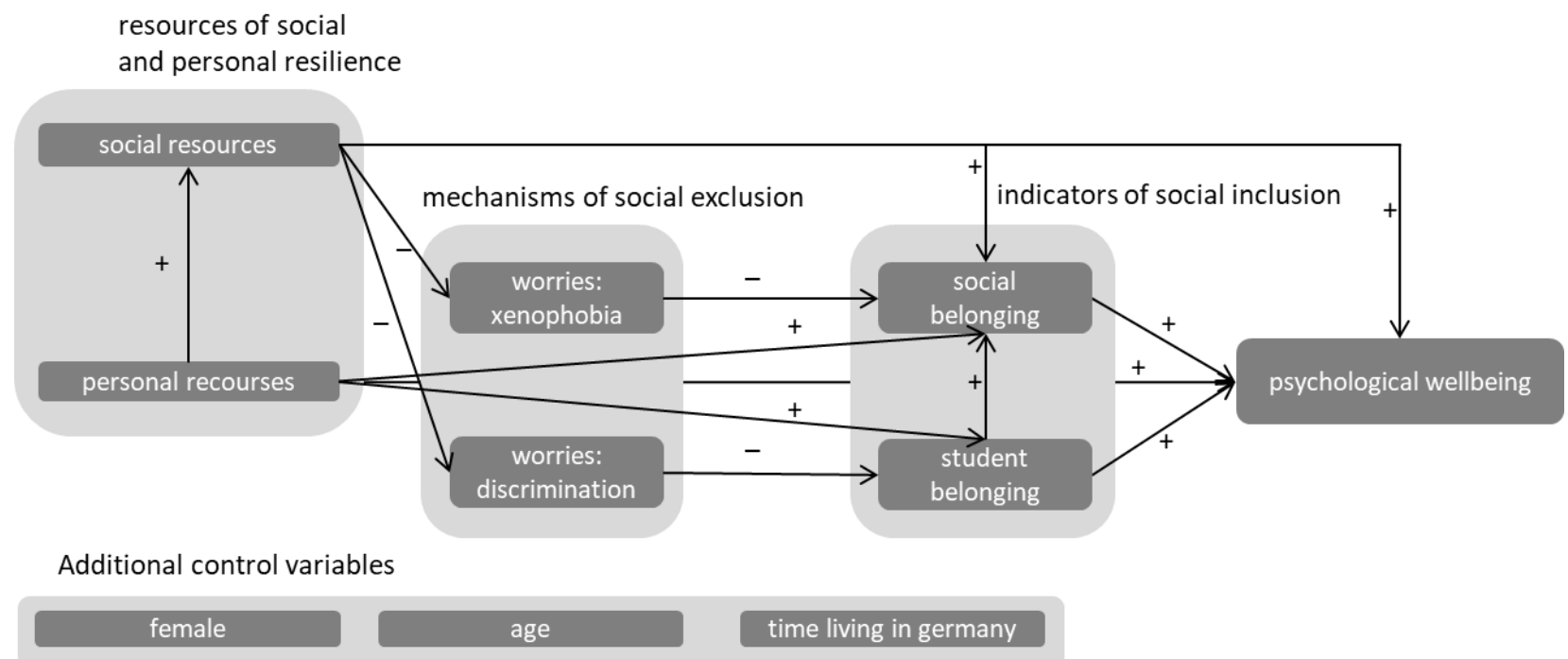

\section{Method}

\section{Participants and Data Collection}

Data was collected from the project, Refugees' Pathways to German Higher Education Institutions (WeGe), funded by the German Federal Ministry of Education and Research. Fieldwork was done in the winter semester of 2018/2019 at HEIs, providing study preparation courses for international and refugee students. During these courses, students are prepared for the necessary examinations for university admission. Depending on the evaluation of their foreign university entrance qualification, they usually have to prove their German language skills at the high C1 level of the Common European Framework of Reference for Languages (CERFL) or have to prevail in the subject-specific so-called 'Feststellungsprüfung' at a 'Studienkolleg' (Schröder, Grüttner, \& Berg, 2019). Since many refugees and international students are preparing for studies in Germany at the same HEIs, both groups can be considered comparatively in corresponding preparatory courses. Eighteen HEIs (Research universities, Universities of Applied Sciences, 'Studienkollegs') were visited for data collection, using paper and pencil questionnaires. In most cases this was done within the regular course environment and time slot, a strategy, that leads to high participation rates. One thousand and nineteen questionnaires were collected and a final analysis sample of 904 observations was gathered. HEIs were chosen by means of regional diversity all over Germany. Questionnaires were composed in both German and English languages and around $90 \%$ of the participants chose German. Information was collected about the formal residence status and whether participants had applied for asylum in Germany.

\section{Measurement}

Psychological wellbeing was measured by means of the WHO5 short scale (Sirpal, Haugen, Sparle, \& Haavet, 2016). This scale that consists of five items, including, for example, "Over the last two weeks I have felt cheerful and in good spirits" ( $\alpha>$ .8). Since the original response scale was from positive "all of the time" (1) to negative "at no time" (6), the scale has been reversed for easier interpretation. To measure social belonging to society as a whole we asked if students "feel that you are part 
of society and be included or do you rather feel excluded?" was measured using a rating of feeling excluded (1) to included (7) (Gundert \& Hohendanner 2014, for a very similar item). Student belonging was assessed by asking how close they feel and belong to the group of students, on a scale of 1 (no overlap self/university students) to 7 (full overlap self/university students) (Janke, Rudert, Marksteiner, \& Dickhäuser, 2017, for a very similar item). A two item short scale regarding worries about xenophobia in Germany (for instance, "I am worried about anti-foreigner sentiment and xenophobia in Germany.") and a two item short scale of anticipated discrimination at HEIs (for instance, "I think university is about my performance, not my background.") with a five point Likert-scale from 1 "not apply at all" to 5 "fully applies" for every item. We distinguished between two aspects of social resources: 1) social resources in general and 2) belongingness to the preparation course in particular. Social resources in general was assessed through the measurement very similar to the idea of Lin (1982), capturing instrumental as well as socio-emotional and learning resources (for instance, "Do you know someone who can help you fill in forms and applications?", $\alpha>.8$ ). A short scale of three questions (for instance, “[...] that I really belong in my preparatory course." or "that I can really trust my teachers", $\alpha>.6$ ) indicated to what extent students feel closely related to their preparation course. Personal resources were measured using the brief resilient coping scale (Sinclair \& Wallston, 2004) that showed moderate internal consistency $(\alpha>$.6). "I think I can develop further if I deal with difficult situations." for an example item, that could apply more or less.

\section{Sample and Variable Description}

About one third of the sampled students had applied for asylum. Asylum applicants in the study sample reported a somewhat lower level of wellbeing than do other international students (3.5 to 3.8). While refugee students in the sample felt more included in society as a whole (4.6 to 4.4), their student belonging level was much lower, compared to the international students (4.7 to 5.1). Refugee students within our sample reported higher levels of worries about xenophobia.(3.1 to 2.5). In the present data, refugee students reported less social resources in general (1.9 to 2.2) but equal course belongingness, as compared to international students (3.7). Refugee students tended to report somewhat more resilient coping behaviours than other international students (3.8 to 3.7). Moreover, the data revealed an underrepresentation of female refugees. Only about $20 \%$ of these are females. Refugee students are of a higher age (26 to 21 years) and reported a longer period of stay, as compared to the comparison group (2.7 to 0.6 years).

\section{Table 1}

Description of Variables

\begin{tabular}{|c|c|c|c|c|c|c|}
\hline \multirow[b]{2}{*}{ psychological wellbeing (WB) } & \multicolumn{2}{|c|}{ Ranges } & $\begin{array}{l}\text { Ref } \\
\text { stu }\end{array}$ & $\begin{array}{l}\text { gee } \\
\text { ents } \\
\text { eans/ } \\
\text { andarc }\end{array}$ & $\begin{array}{r}\text { Intern } \\
\text { stud } \\
\text { portio } \\
\text { eviatio }\end{array}$ & $\begin{array}{l}\text { ational } \\
\text { ents } \\
\text { is } \\
\text { n) }\end{array}$ \\
\hline & 1 & 6 & 3.5 & $(1.1)$ & 3.8 & $(1.0)$ \\
\hline social belonging (SO) & 1 & 7 & 4.6 & $(1.4)$ & 4.4 & $(1.3)$ \\
\hline student belonging (ST) & 1 & 7 & 4.7 & $(1.6)$ & 5.1 & $(1.4)$ \\
\hline worries: xenophobia (WX) & 1 & 5 & 3.1 & $(1.2)$ & 2.5 & $(1.1)$ \\
\hline worries: discrimination (WD) & 1 & 5 & 2.8 & $(1.2)$ & 2.5 & $(1.1)$ \\
\hline social resources (SR) & 1 & 3 & 1.9 & $(0.5)$ & 2.2 & $(0.5)$ \\
\hline course belonging $(\mathrm{CB})$ & 1 & 5 & 3.7 & $(0.8)$ & 3.7 & $(0.8)$ \\
\hline resilient coping (RC) & 1 & 5 & 3.8 & $(0.6)$ & 3.7 & $(0.6)$ \\
\hline female (FE) & 0 & 1 & 0.2 & $(0.4)$ & 0.5 & $(0.5)$ \\
\hline age (AG) & 16 & 55 & 26.0 & $(4.8)$ & 21.3 & (3.9) \\
\hline time living in Germany (TG) & 0 & 13 & 2.7 & $(1.2)$ & 0.6 & $(1.7)$ \\
\hline $\mathrm{N}$ & & & 296 & 329 & 635 & 666 \\
\hline
\end{tabular}

Source: Study Preparation Survey 2018 within the project WeGe 


\section{Empirical Modelling}

Structural equation modelling (SEM) was used with the statistics program Stata (Acock, 2013). SEM assists in dealing with missing values by estimating the full information maximum likelihood model as well as looking at direct and indirect effects to evaluate the role of mediators. Wald-tests provide evidences of group differences of the model coefficients. In a second step, multivariate regressions with control variables and interaction effects were modelled to examine whether there was a moderation of social exclusion mechanisms through social or personal resources. Significant interactions indicated buffer effects and a specific type of resilience. Continuous variables were centered at the mean to calculate and visualise the interaction effects. Visualisation has been used to provide a meaningful interpretation (Jann, 2014).

\section{Results}

\section{Wellbeing of International Students}

Starting with the international students' psychological wellbeing, Table 2 shows the direct effects within a SEM, covering the variables and associations presented in Figure 2. The goodness of fit indices are satisfactory (RMSEA, .02; CFI, .99; TFI, .97). This indicates that the proposed conceptual model fits the observed data well. Possible additional paths within the model are not necessary. Before discussing existing group differences, the direct effects of independent variables on dependent variables are presented. The first path within the model involves resilient coping to course belonging and reveal a positive effect (.14). Despite this effect of resilient coping on the first aspect of social resources, for the second aspect - social resources in general, resilient coping is irrelevant. Course belongingness also strengthens social resources outside the course context (.21), and thus, an indirect path from resilient coping over course belonging to general social resources is established. Worries about xenophobia are influenced by course belonging (-.18) and general social resources (-.11); concerns decrease with stronger social resources.

\section{Table 2}

International Students' Psychological Wellbeing, Direct Effects (SEM)

\begin{tabular}{|c|c|c|c|c|c|c|c|c|c|c|c|c|c|c|c|}
\hline \multirow[b]{2}{*}{ resilient coping (RC) } & \multirow{2}{*}{$\frac{\mathrm{RC}}{--}$} & \multicolumn{2}{|c|}{$\mathrm{CB}$} & \multicolumn{2}{|l|}{ SC } & \multicolumn{2}{|c|}{ WX } & \multicolumn{2}{|c|}{ WD } & \multicolumn{2}{|l|}{ ST } & \multicolumn{2}{|c|}{ SO } & \multicolumn{2}{|c|}{ WB } \\
\hline & & .14 & $*$ & -.05 & & & & & & .09 & $*$ & .08 & $*$ & .14 & * \\
\hline course belonging $(\mathrm{CB})$ & & -- & & .21 & $*$ & -.18 & $*$ & -.07 & $*$ & .30 & $*$ & .11 & $*$ & .16 & $*$ \\
\hline social resources (SR) & & & & -- & & -.11 & $*$ & .06 & & .16 & $*$ & .07 & $*$ & .13 & * \\
\hline worries: xenophobia (WX) & & & & & & -- & & .56 & $*$ & & & -.19 & $*$ & -.07 & \\
\hline worries: discrimination (WD) & & & & & & & & -- & & -.03 & & & & -.12 & $*$ \\
\hline student belonging (ST) & & & & & & & & & & -- & & .17 & $*$ & .12 & $*$ \\
\hline social belonging (SO) & & & & & & & & & & & & -- & & .03 & \\
\hline female (FE) & & & & & & & & .12 & $*$ & & & & & .01 & \\
\hline age (AG) & & & & & & & & & & -.12 & $*$ & & & .08 & $*$ \\
\hline time living in Germany (TG) & & & & & & & & & & & & & & -.11 & $*$ \\
\hline psychological wellbeing (WB) & & & & & & & & & & & & & & -- & \\
\hline
\end{tabular}

Own calculation: Study Preparation Survey 2018, N = 627 international students without asylum application, Structural Equation Modelling with Full Information Maximum Likelihood, goodness of fit: $\mathrm{p}>\mathrm{Chi} 2=.16$, RMSEA $=.02, \mathrm{CFI}=.99$, TFI $=.97$, * indic ate significance of effects at $\mathrm{p}$-value $<.10$, boldface standardized coefficents indicate group differences (Wald-test).

As proposed in the conceptual model above, course belongingness reduces worries about discrimination at HEIs (-.07), however, general social resources do not. There is a strong association between worries about xenophobia and worries about discrimination at HEIs that may not be surprising. Against expectations, worries about discrimination have no effect on student belongingness. Belongingness to a group of university students is primarily determined by belongingness to the preparatory course (.30), which indicates the important role of preparatory courses in encouraging social integration at universities. Student belonging, in turn, is positively related to social belonging to society as a whole (.17). Xenophobia is proven as having a 
detrimental effect (-.19). One key proposition of the conceptual model above is the positive effect of resilient coping on indicators of social inclusion. This proposition holds for student belonging (.09) and social belonging (.08). Levels of psychological wellbeing are directly related to resilient coping (.14), course belonging (.16), general social resources (.13), worries about discrimination (-.12) and student belonging (.12). Beyond these direct paths, an indirect path is observable starting from resilient coping to course belonging via reduced worries and increased student and social belonging, leading towards strengthened wellbeing.

\section{Wellbeing of Refugee Students in Comparison}

For refugee students, direct effects can be observed regarding resilient coping on course belonging. What is different, compared to international students, is the strength of the effect; for refugees it is stronger (.28). For refugee students, course belongingness does not influence social resources, but social resources ease worries about xenophobia (-.15) and discrimination (-.21). The association between the two types of worries is still important, but much lower compared to international students (.38). Most of the other specified effects are quite similar and are not significantly different. Only the indicators of social belonging work completely differently. While student belonging is irrelevant, social belonging to society as a whole has the strongest direct effect on wellbeing (.18). There is no direct effect of resilient coping on wellbeing, but the indirect path mentioned above seems to be of importance - resilient coping encourages course belonging which, by mediation of student belonging, facilitates social belonging (.24).

Table 3

Refugee Students' Psychological Wellbeing, Direct Effects (SEM)

\begin{tabular}{|c|c|c|c|c|c|c|c|c|c|c|c|c|c|}
\hline & $\mathrm{RC}$ & $\mathrm{CB}$ & & SC & $w X$ & & WD & ST & & so & & WB & \\
\hline resilient coping $(\mathrm{RC})$ & -- & .28 & $*$ & -.07 & & & & .11 & $*$ & .11 & * & .05 & \\
\hline course belonging $(\mathrm{CB})$ & & -- & & -.03 & -.02 & & -.10 & .13 & $*$ & .03 & & .12 & $*$ \\
\hline social resources (SR) & & & & -- & -.15 & $*$ & -.21 & .16 & $*$ & -.02 & & .05 & \\
\hline worries: xenophobia (WX) & & & & & -- & & .38 & $*$ & & -.24 & $*$ & -.11 & $*$ \\
\hline worries: discrimination (WD) & & & & & & & -- & -.09 & & & & -.12 & $*$ \\
\hline student belonging (ST) & & & & & & & & -- & & .24 & * & .01 & \\
\hline social belonging (SO) & & & & & & & & & & -- & & .18 & $*$ \\
\hline female (FE) & & & & & & & .04 & & & & & .01 & \\
\hline age $(A G)$ & & & & & & & & -.07 & & & & .08 & \\
\hline time living in Germany (TG) & & & & & & & & & & & & -.03 & \\
\hline psychological wellbeing (WB) & & & & & & & & & & & & -- & \\
\hline
\end{tabular}

Own calculation: Study Preparation Survey 2018, N = 277 refugee students with asylum application, Structural Equation Modelling with Full Information Maximum Likelihood, goodness of fit: RMSEA $=.02, \mathrm{CFI}=.99, \mathrm{TFI}=.97$, * indicate significance of effects at $\mathrm{p}$-value $<.10$, boldface standardized coefficents indicate group differences (Wald-test).

\section{Resilience Manifested in Interaction Effects}

For analysing resilience, it is crucial to look at interactions between stressors and resources. All possible interactions between indicators of social exclusion and inclusion were calculated for both student groups of interest. Only two significant interactions where found and are reported here. First, for refugee students, suffering from xenophobia is conditional on the level of course belonging (Figure 2, left). For very low levels of course belonging, the detrimental effect is about -.32 standard deviations, and highly significant. With higher levels of course belonging, the effect decreases to -.06, and turns insignificant. Second, the effect of student belonging is conditional to the level of belonging to society as a whole (Figure 2, right). Under condition s of very low social belonging, a negative but insignificant tendency can be observed (-.13). With higher levels of social belonging, the effect of student belonging increases to .18. While there is no primary effect of student belongingness of refugees, this interaction indicates the important role of student belonging within a broader picture of integration in the host society. 


\section{Figure 2}

Buffer Effect of Course Belonging and Boost Effect of Social Belonging

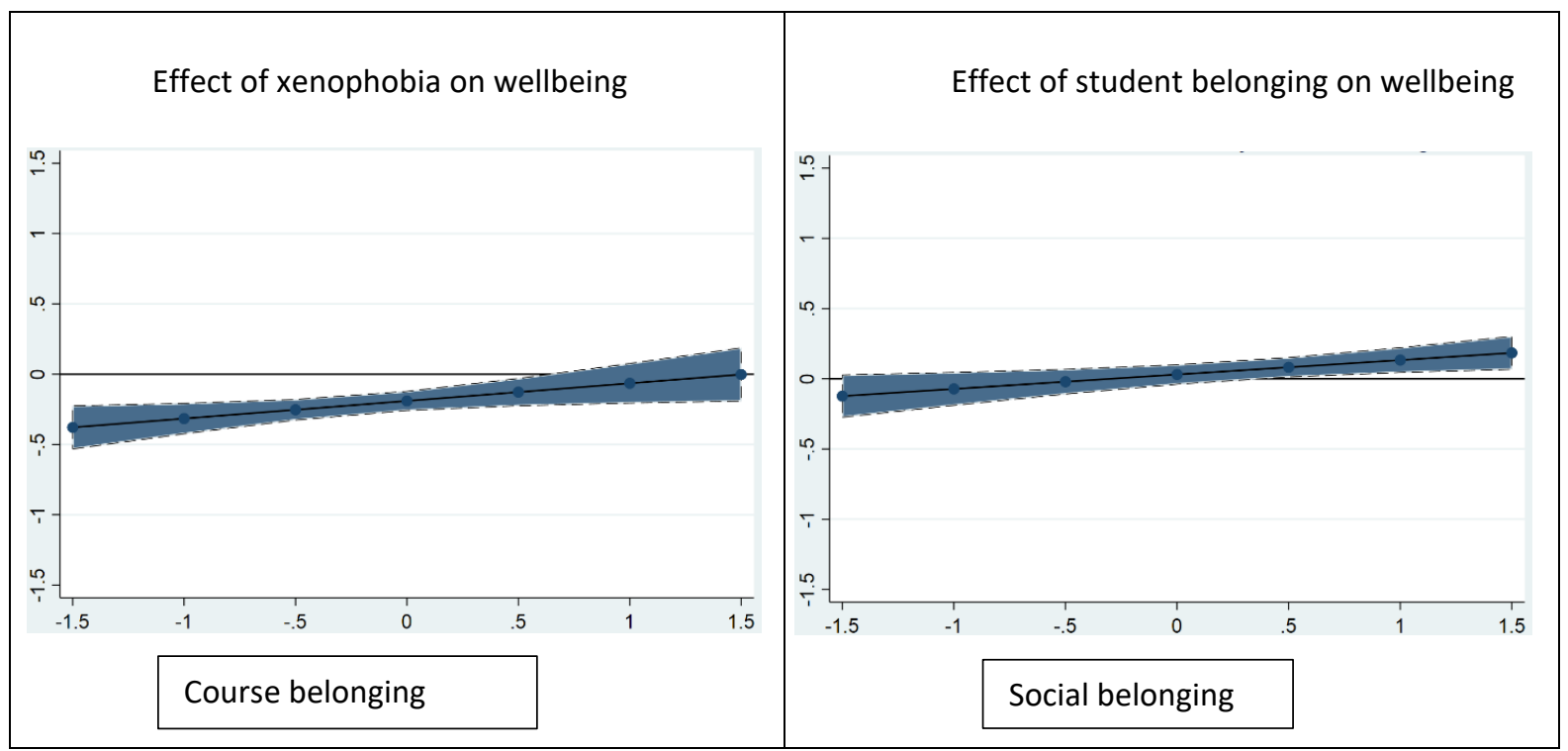

Source: Study Preparation Survey 2018, linear regressions with control variables (female, age, length of stay) and interactions, clustered standard errors. Refugee students only $(\mathrm{N}=272)$. Variables are standardised with mean 0 and standard deviation 1 . For example: The effect of student belonging on wellbeing is about -.3 standard deviations conditional on course belonging at the level of -1 standard deviations.

\section{Discussion}

The results point to the negative consequences of worries about xenophobia and discrimination for the psychological wellbeing of international and refugee students. These mechanisms of social exclusion can hamper learning and study preparation success and thereby threaten academic careers of international students and integration strategies of refugee students. Personal resources of resilience like resilient coping can strengthen feelings of belonging against the backdrop of perceived xenophobia. In particular for refugee students a higher level of resilient coping acts indirectly as reinforcements of wellbeing via encouraged course and social belonging. For refugee students, social belonging is more important for psychological wellbeing than student belonging, while for other international students the situation is totally opposite. Results indicate that course belonging can buffer the negative effects of worries about xenophobia on the psychological wellbeing of refugee students. Strong feelings of belonging to society within refugee students can boost the positive effect of student belonging. While psychological wellbeing of international students is directly influenced by their sense of student belonging, for refugee students, this influence works only indirectly via a stronger sense of social belonging to society as a whole.

Refugee students profit most if study preparation and the perspective of becoming a university student are clearly associated with social integration within the host country society. Thus asylum and residence policies should consider higher education as a means of social integration. HEIs should encourage the resilient coping behaviours of refugee students as well as give effort in facilitating the feeling of belonging to preparatory courses and society. In doing so, HEIs can act as a barrier against the detrimental effects of a xenophobic societal climate when providing an environment that fosters social and academic belonging. Ultimately, counteracting a racist and xenophobic climate remains a concerted effort in society as a whole.

\section{Acknowledgements}

The project Refugees' Pathways into German Higher Education Institutions (WeGe) and the present article was funded by the Federal Ministry of Education and Research (BMBF) under the research grant 01PX16015. 


\section{References}

Acock, A. C. (2013). Discovering structural equation modeling using stata. Stata Press.

Akhtar, M., \& Kroener-Herwig, B. (2015). Acculturative stress among international students in context of socio-demographic variables and coping styles. Current Psychology, 34(4), 803-815. https://doi.org/10.1007/s12144-015-9303-4

Akhtar, M., \& Kroener-Herwig, B. (2017). Coping styles and socio-demographic variables as predictors of psychological well-being among international students belonging to different cultures. Current Psychology, 34(4), 803. https://doi.org/10.1007/s12144-017-9635-3

Apolinarski, B., \& Brandt, T. (2018). Ausländische Studierende in Deutschland 2016: Ergebnisse der Befragung bildungsausländischer Studierender im Rahmen der 21. Sozialerhebung [Foreign Students in Germany 2016: Results of the Survey of Foreign Students in the 21st Social Survey]. Berlin: Bundesministerium für Bildung und Forschung.

Baker, S., Irwin, E., Freeman, H., Nance, S., \& Coleman, J. (2018). Building cultural and linguistic bridges: Reflections on a program designed to support adult students from refugee backgrounds' transitions into university. Journal of Academic Language \& Learning, 12(1), 64-80.

Brooker, A., \& Lawrence, J. A. (2012). Educational and Cultural Challenges of Bicultural Adult Immigrant and Refugee Students in Australia. Australian Journal of Adult Learning, 52(1), 66-88.

Bude, H., \& Lantermann, E.-D. (2006). Soziale exklusion und exklusionsempfinden [Social exclusion and feelings of exclusion]. Kölner Zeitschrift für Soziologie und Sozialpsychologie, 58(2), 233-252. https://doi.org/10.1007/s11575006-0054-1

Byrne, D. (2005). Social exclusion. Open University Press.

Chen, H.-J., Mallinchrodt, B., \& Mobley, M. (2002). Attachment patterns of East Asian international students and sources of perceived social support as moderators of the impact of U.S. racism and cultural distress. Asian Journal of Counselling, 9(1/2), 27-48.

Correa-Velez, I., Gifford, S. M., \& McMichael, C. (2015). The persistence of predictors of wellbeing among refugee youth eight years after resettlement in Melbourne, Australia. Social Science \& Medicine, 142, 163-168. https://doi.org/10.1016/j.socscimed.2015.08.017

Crea, T. M. (2016). Refugee higher education: Contextual challenges and implications for program design, delivery, and accompaniment. International Journal of Educational Development, 46, 12-22. https://doi.org/10.1016/j.ijedudev.2015.11.005

Findlay, A. M. (1990). A migration channels approach to the study of high-level manpower movements: A theoretical perspective. International Migration, 28(1), 15-23. https://doi.org/10.1111/j.1468-2435.1990.tb00132.x

Grüttner, M., Schröder, S., Berg, J., \& Otto, C. (2018). Refugees on Their Way to German Higher Education: A Capabilities and Engagements Perspective on Aspirations, Challenges and Support. Global Education Review, 5(4), 115-135. https://ger.mercy.edu/index.php/ger/article/view/456

Gundert, S., \& Hohendanner, C. (2014). Do fixed-term and temporary agency workers feel socially excluded? Labour market integration and social well-being in Germany. Acta Sociologica, 57(2), 135-152.

Hahn, E., Richter, D., Schupp, J., \& Back, M. D. (2019). Predictors of refugee adjustment: The importance of cognitive skills and personality. Collabra: Psychology, 5(1), 23. https://doi.org/10.1525/collabra.212

Hobfoll, S.E. (2001). The influence of culture, community, and the nested-self in the stress process: Advancing conservation of resources theory. Applied Psychology: An International Review, 50(3), 337-421

Janke, S., Rudert, S. C., Marksteiner, T., \& Dickhäuser, O. (2017). Knowing one's place: Parental educational background influences social identification with academia, test anxiety, and satisfaction with studying at university. Frontiers in Psychology, 8, 1326. https://doi.org/10.3389/fpsyg.2017.01326

Jann, B. (2014). Plotting regression coefficients and other estimates. The Stata Journal, 14(4), 708-737.

Jung, E., Hecht, M. L., \& Wadsworth, B. C. (2007). The role of identity in international students' psychological well-being in the United States: A model of depression level, identity gaps, discrimination, and acculturation. International Journal of Intercultural Relations, 31(5), 605-624. https://doi.org/10.1016/j.ijintrel.2007.04.001

Lazarus, R. S., \& Folkman, S. (1984). Stress, appraisal, and coping. Springer.

Leary, M. R. (1990). Responses to social exclusion: Social anxiety, jealousy, loneliness, depression, and low self-esteem. Journal of Social and Clinical Psychology, 9(2), 221-229. https://doi.org/10.1521/jscp.1990.9.2.221

Lin, N. (1982). Social resources and instrumental action. In P. V. Marsden \& N. Lin (Eds.), Social structure and network analysis (pp. 131-145). Sage.

Molla, T. (2019). Educational aspirations and experiences of refugee-background African youth in Australia: A case study. International Journal of Inclusive Education, 8(3), 1-19. https://doi.org/10.1080/13603116.2019.1588924 
Sandoz, L. (2018). Understanding access to the labour market through migration channels. Journal of Ethnic and Migration Studies, 66(1), 1-20. https://doi.org/10.1080/1369183X.2018.1502657

Schröder, S., Grüttner, M., \& Berg, J. (2019). Study Preparation for Refugees in German 'Studienkollegs' - Interpretative Patterns of Access, Life-wide (Language) Learning and Performance. Widening Participation and Lifelong Learning, 21(2), 67-85.

Sinclair, V. G., \& Wallston, K. A. (2004). The development and psychometric evaluation of the Brief resilient coping scale. Assessment, 11(1), 94-101. https://doi.org/10.1177/1073191103258144

Sirpal, M. K., Haugen, W., Sparle, K., \& Haavet, O. R. (2016). Validation study of HSCL-10, HSCL-6, WHO-5 and 3-key questions in 14-16 year ethnic minority adolescents. BMC Family Practice, 17, 7. https://doi.org/10.1186/s12875-016$\underline{0405-3}$

Sullivan, C., \& Kashubeck-West, S. (2015). The interplay of international students' acculturative stress, social support, and acculturation modes. Journal of International Students, 5(1), 1-11.

Täubig, V. (2019). Work as real life in the context of organised disintegration - a perspective on the everyday life of refugees. Identities, 26(3), 339-355. https://doi.org/10.1080/1070289X.2019.1609806

Ungar, M., \& Hadfield, K. (2019). The differential impact of environment and resilience on youth outcomes. Canadian Journal of Behavioural Science/Revue canadienne des sciences du comportement, 51(2), 135-146. https://doi.org/10.1037/cbs0000128

Williams, K. D. (2007). Ostracism. Annual Review of Psychology, 58, 425-52. https://doi.org/10.1146/annurev.psych.58.110405.085641

\section{Please cite this article as:}

Grüttner, M. (2019). Belonging as a resource of resilience: Psychological wellbeing of international and refugee students in study preparation at German higher education institutions. Student Success, 10(3), 36-44. https://doi.org/10.5204/ssj.v10i3.1275

This article has been peer reviewed and accepted for publication in Student Success. Please see the Editorial Policies under the 'About' section of the Journal website for further information.

Student Success: A journal exploring the experiences of students in tertiary education

(c) (1) This work is licensed under a Creative Commons Attribution 4.0 International Licence. As an open access journal, articles are free to use with proper attribution. ISSN: 2205-0795 